\title{
INTERthesis
}

DOUTORADO INTERDISCIPLINAR EM CIÊNCIAS HUMANAS - UFSC - FLORIANÓPOLIS - SC - BRASIL

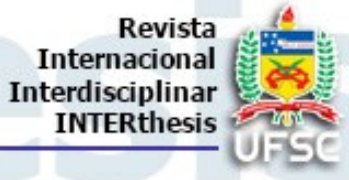

\section{PROGRAMA NACIONAL DE ALIMENTAÇÃO ESCOLAR: OS DESCOMPASSOS NAS PRÁTICAS DE SUA IMPLEMENTAÇẪO.}

Manuela Diamico ${ }^{1}$

\section{Resumo:}

O Programa Nacional de Alimentação Escolar (PNAE) propõe fornecer alimentação adequada e educação alimentar e nutricional a todos os estudantes do ensino básico da rede pública. Sua implementação tem sido analisada e avaliada principalmente pelas áreas da saúde pública e gestão de recursos naturais. A partir da teoria da transição e de outros referenciais sociológicos, nosso objetivo é avaliar o potencial do PNAE para desenvolver práticas alimentares efetivamente mais saudáveis e sustentáveis. $\mathrm{O}$ trabalho empírico consistiu em entrevistas com atores importantes envolvidos na implementação do PNAE em escolas estaduais em Florianópolis, Santa Catarina, principalmente em função do processo de terceirização da implementação do programa. Entre as principais conclusões destacamos a recepção negativa do alimento saudável pelos atores envolvidos nas escolas, pois confronta-se com o imaginário que liga infância à ingestão de grande quantidade de açúcares de baixa qualidade. Também avaliamos como um problema relevante para a efetivação dos objetivos do PNAE a terceirização da Alimentação Escolar, ao dificultar a sintonia entre os diferentes saberes e percepções sobre os alimentos saudáveis e sustentáveis. Apesar destes problemas, o programa tem potencial para influenciar novas práticas alimentares, caso se diminuam as distâncias simbólicas sobre os entendimentos do que seria saudável e sustentável.

Palavras-chave: Programa Nacional de Alimentação Escolar. Sustentabilidade. Teoria da Transição. Práticas Alimentares.

\section{BRAZILIAN SCHOOL FEEDING PROGRAM: THE IMBALANCE IN ITS IMPLEMENTATION}

\begin{abstract}
:
The Brazilian School Feeding Program (PNAE in Portuguese), aims to provide adequate food intake and food and nutrition education for all the elementary public school students in Brazil. Its implementation has been chiefly analyzed and evaluated by public health and food studies. Based on the transition theory and other sociological references, we aim to evaluate the PNAE's potential to develop new and effectively more healthy and sustainable food practices. The empiric research consisted of interviews with main actors in the implementation of the PNAE at the local level in Florianópolis city, Santa Catarina. Amid the conclusions, we highlight the healthy food negative reception by local actors, whose imaginary links childhood
\end{abstract}

\footnotetext{
${ }_{1}^{1}$ Doutora em Sociologia Polícia pela Universidade Federal de Santa Catarina, Florianópolis, SC. Pósdoutoranda do Programa de Pós-Graduação Interdisciplinar em Ciências Humana na mesma universidade. E-mail: manudiamico@gmail.com
} 
with large consumption of low-quality sugar. The analysis also indicates the outsourcing of service as a relevant problem that undermines the program implementation. This outsourcing mechanism blocks the exchange knowledge and perceptions on healthy food and sustainability among the different actors, taking the process of construction of the program distant from the PNAE's goals. Despite these problems, we believe the PNAE can be able to influence new food practices if the symbolic distance between healthy and sustainable food understandings get reduced.

Keywords: National School Feeding Program. Sustainability. Transition Theory. Food Practices

\section{PROGRAMA NACIONAL DE ALIMENTACIÓN ESCOLAR: LOS DESAJUSTES EN LAS PRÁCTICAS DE SU IMPLEMENTACIÓN}

\section{Resumen:}

El Programa Nacional de Alimentación Escolar (PNAE) tiene como objetivo disponibilizar alimentación adecuada y educación alimentaria y nutricional para todos los estudiantes de la enseñanza básica en la red pública de educación. Su implementación ha sido analizada y evaluada principalmente por las áreas de salud pública y gestión de recursos naturales. A partir de la teoría de transición y de otros referentes sociológicos, nuestro objetivo es evaluar el potencial del PNAE para desarrollar prácticas alimentarias efectivamente más saludables y sostenibles. El campo empírico de esta investigación consistió en entrevistar actores involucrados en la implementación del PNAE en las escuelas del estado de Santa Catarina, ubicadas en Florianópolis. Entre las principales conclusiones, presentamos la recepción negativa del alimento saludable por los actores involucrados en las escuelas, una vez que su imaginario relaciona la infancia con la ingestión de gran cantidad de azúcares de baja calidad, o sea, tienen una perspectiva opuesta a la del Programa. Además, evaluamos que la tercerización de la Alimentación Escolar se plantea como un problema relevante para la concreción de los objetivos del PNAE, pues dificulta la sintonía entre los distintos saberes y percepciones sobre los alimentos saludables y sostenibles. Sin embargo, a pesar de estos problemas, el programa tiene la potencialidad de influenciar nuevos hábitos alimentarios, si se disminuyen las distancias simbólicas entre los entendimientos de lo que sería saludable y sostenible.

Palabras clave: Programa Nacional de Alimentación Escolar. Sustentabilidad.

Teoría de la Transición. Prácticas alimentarias. 


\section{INTRODUÇÃO}

O Programa Nacional de Alimentação Escolar (PNAE), uma das políticas mais antigas do país, originada na década de 1950, é realizado por meio do repasse de recursos financeiros aos estados, municípios, escolas federais ou instituições filantrópicas, para compra de alimentos para estudantes de toda a educação básica. O objetivo é oferecer "alimentação escolar e ações de educação alimentar e nutricional a estudantes de todas as etapas da educação básica pública2" (FNDE, 2017).

Seus direcionamentos são constantemente atualizados, orientando-se para as estratégias internacionais de responsabilidade pública na alimentação escolar. A partir dos movimentos que levam à constitucionalização do direito à alimentação, no artigo 208 da Constituição Federal de 1988, verifica-se uma mudança significativa na abordagem sobre o tema por parte do governo, conduzindo a reformulações substanciais que convergem para o Direito Humano à Alimentação Adequada (DHAA). Essa mudança permite o entendimento de que o fornecimento da Alimentação Escolar (AE) é um direito do cidadão e não apenas uma política assistencialista.

A nova perspectiva se consolida em uma abordagem interdisciplinar que passa a combinar a alimentação saudável com sustentabilidade ambiental e saúde pública, numa abrangência nacional (MINISTÉRIO DA SAÚDE \& MINISTÉRIO DA EDUCAÇÃO, 2006). Além disso, passa-se a olhar o potencial pedagógico do programa, ensejando e incentivando o potencial educativo que a alimentação escolar (AE) pode ter no ensino público.

Neste artigo, focamos o processo de Educação Alimentar e Nutricional (EAN) proposta pelo PNAE e nos perguntamos: como acontece sua implementação nas escolas? Quais são os atores envolvidos e seus papéis nesse processo educativo? Entendemos que o PNAE tem potencial para influenciar o processo de transição para novas práticas alimentares saudáveis e sustentáveis, uma vez que está inserido no ambiente educacional e inclui mecanismos de EAN (FNDE, 2013). Assim, nosso objetivo é analisar os limites e potencialidades na sua implementação e no desenvolvimento de um senso crítico nos estudantes, preocupado com sustentabilidade e saúde.

${ }^{2}$ FNDE. Sobre o PNAE. 2017. Disponível em: http://www.fnde.gov.br/programas/pnae. Acesso em 28 nov. 2018. 
O artigo está dividido em 5 partes. Primeiramente, apresentamos nossa metodologia; em seguida expomos nosso referencial teórico, que serve de lente para observar nosso objeto PNAE; na terceira parte, situamos brevemente o contexto de surgimento dos Programas de Alimentação Escolar e a influência internacional dos debates sobre Direito Humano à Alimentação Adequada (DHAA); na sequência, apresentamos os dados de pesquisa, focando a percepção dos atores sobre os conceitos de Alimentação Adequada (AA) e na Educação Alimentar e Nutricional (EAN), como proposto pelo PNAE - isso porque, se o objetivo do PNAE é ensinar para os estudantes sobre esses conceitos, supomos que os atores envolvidos na sua implementação tenham clareza sobre eles; por fim, destacamos os pontos de entrave que podem ser melhor trabalhados na implementação do PNAE. Veremos que o mecanismo de terceirização da Alimentação Escolar (AE) vem tomando conta do formato da intervenção e tem impactado direta e negativamente na efetivação do Programa, principalmente com relação à EAN.

\section{METODOLOGIA}

A pesquisa baseou-se em revisão bibliográfica sobre o PNAE no Brasil e sobre Programas de Alimentação Escolar nacionais e internacionais. Esse referencial ajuda a compreender o movimento de surgimento dos Programas de Alimentação Escolar (PAEs) dentro de uma perspectiva global.

Realizamos, também, uma pesquisa de campo qualitativa e de caráter exploratório para identificação dos atores envolvidos na implementação do PNAE e dos papeis por eles desempenhados. Com este trabalho, procuramos contribuir, a partir da Sociologia, com outras pesquisas de outras áreas disciplinares.

Para tanto, efetuamos visitas às escolas estaduais Escola Estadual Presidente Roosevelt, Escola Henrique Stodieck e Escola Getúlio Vargas, em Florianópolis. Nelas, conversamos com os diretores para obter informações sobre o PNAE nas escolas. Nas últimas duas escolas, a informação passada foi que a empresa terceirizada é quem realiza o PNAE, não sendo da alçada da diretoria da escola, e que, portanto, não poderiam ajudar. Na escola Presidente Roosevelt, tivemos abertura e aceitação por parte da diretora, que nos possibilitou acompanhar o horário de intervalos para as refeições e conversar com 3 professoras, com a merendeira e com alunos. Organizou-se, com uma das professoras de biologia, uma 
discussão com os estudantes do $8^{\circ}$ ano, com base em uma edição, feita por nós, do filme "Super Size Me", focando as discussões sobre AE.

Contactamos também o Centro Colaborador em Alimentação e Nutrição Escolar de Santa Catarina (CECANE-SC), o Conselho Estadual de Alimentação (CEAE-SC), a Secretaria de Educação e a Empresa Terceirizada que fornece AE nas escolas de Santa Catarina. A troca de informações e experiências com a equipe do CECANE foi muito importante, pois nos possibilitou acompanhar um dos cursos de formação para agentes do PNAE, oferecido pelo próprio CECANE, para os municípios da regional de Criciúma. A formação foi direcionada para gestores, merendeiras, agricultores, CAEs e nutricionistas municipais. Por ocasião das visitas e participação no curso (onde entrevistamos alguns atores), pudemos realizar, no total, 14 entrevistas semiestruturadas, com os atores envolvidos na implementação do programa: Diretora (1) professoras (5), merendeira (1), nutricionistas (2), agricultores (2) e membros do CECANE-SC (3).

\section{TRANSIÇÃO PARA NOVAS PRÁTICAS ALIMENTARES}

A teoria das transições (HINRICHS, 2014; SPAARGAREN; OOSTERVEER; LOEBER, 2012) analisa os eventos sociais olhando para a complexidade que as múltiplas dimensões das transformações societais tem no desenvolvimento sustentável. O princípio base é entender a transição como um processo de mudanças não lineais e estruturais nos cenários cultural, sociotécnico e de governança (SPAARGAREN; OOSTERVEER; LOEBER, 2012). Analisar esses cenários envolve uma perspectiva multinível, que coloca em movimento 3 planos: o plano do nicho, que representa as práticas societais dinâmicas (consumo, produção e distribuição); o plano dos regimes, que refere-se às escolhas sociotécnicas de produção da vida, ou seja, às tecnologias disponíveis e consideradas aceitáveis; e, por último, o plano do landscape, referindo-se aos contextos dinâmicos e não premeditados, mas que impactam nas escolhas e práticas cotidianas e na governança dos recursos. Spaargaren, Oosterveer e Loeber (2012) chamam a atenção para duas dinâmicas no landscape atual: o relatório Bruntland (1991), que denuncia pela primeira vez de maneira sistemática a preocupação com a escassez dos recursos naturais, e o processo de globalização, que expande aquela preocupação, colocando o problema ambiental na agenda global. 
Assim articulados, esses níveis nos permitem analisar os diferentes aspectos que mobilizam as práticas e o processo de transição para sustentabilidade. Eles possibilitam, ainda, identificar a influência dos elementos contextuais do landscape e a influência dos procedimentos institucionalizados e já internalizados socialmente, como os padrões de práticas e percepções, colocados no nível do regime. Por contraste, viabilizam, também, a identificação de práticas que fogem aos padrões, que contestam e apontam novas problemáticas societárias, ao nível do nicho, que são as práticas alternativas. Essas práticas alternativas podem vir a disputar o status de práticas institucionalizadas ao nível do regime. Ou seja, essa estrutura heurística de níveis serve para balizar os conhecimentos e práticas alternativos ou efetivos, mas reconhece a fluidez desses estágios. Isso quer dizer que uma prática considerada alternativa pode vir a se tornar efetiva e vice-versa.

As transformações promovem novas ideias, estruturas e discursos, bem como novos produtos, objetivos, tecnologias e infraestruturas (SPAARGAREN, OOSTERVEER; LOEBER, 2012). A cadeia alimentar, em particular, tem sido redefinida e transformada diante da crescente influência da insegurança alimentar, dos riscos alimentares, dos protestos públicos contra inovações alimentares (em especial transgenia) e da tendência de produção e consumo alimentar sustentáveis. Como resultado, novas relações de poder podem surgir, entre os atores na cadeia produtiva, organizando e legitimando novas práticas alimentares (ao nível do nicho) que, por sua vez, acabam se institucionalizando (ao nível dos regimes), como é o exemplo de muitas práticas de produção sustentáveis, que começaram como ações singulares e hoje já fazem parte do processo de toda grande indústria, regulamentado institucionalmente. As concepções tradicionalmente voltadas à escassez, apoiadas na tecnificação, na intensificação da produção e na racionalidade da "eficiência produtiva"- baseada no produzir mais com menos -, têm perdido espaço para uma racionalidade voltada para a qualidade e seguridade alimentar, proteção ambiental, conservação da natureza e bem-estar animal, que pode ser definida como eficiência ecológica.

Entendemos as práticas alimentares, portanto, como um lugar onde as regras sociais introjetadas pelos atores se mostram. $O$ agir consiste na interação social entre os atores, em um determinado espaço. Nele, mostram-se os sentidos dessa ação, as negociações entre os atores e os resultados dessa interação. Nas práticas 
cotidianas expressam-se os nexus partilhados que articulam as regras, os saberes e os fazeres entre os atores (HUI; SCHATZKI; SHOVE, 2017)

Essa visão da prática articulada com a teoria das transições permite entender que as transformações podem ser percebidas nas práticas cotidianas e permite identificar as diferentes racionalidades envolvidas no processo de desenvolvimento de ações com o objetivo da sustentabilidade (SCHATZKI, 2013; SHOVE; PANTZAR; WATSON, 2012).

O PNAE abarca dois movimentos que podem ser identificados como nichos, nessa perspectiva e que tem potencial transformador: o da EAN e o da Aquisição de Alimentos da Agricultura Familiar. Embora tenham caráter alternativo, ao serem institucionalizados pelo Programa, estes nichos passam a integrar o regime. Essa integração na prática, no entanto, não é nem rápida nem direta, mas está em andamento.

Para entender a implementação do PNAE, analisamos as interações entre os atores locais envolvidos nas práticas cotidianas. Afinal, como argumenta Guivant (1997), é na interação entre os atores que se desenvolvem novos conhecimentos, com caráter híbrido e próprios do momento histórico. Esses novos conhecimentos são fruto das negociações sociais que envolvem relações de poder, interesses, crenças e desafios cotidianos postos no contexto das práticas sociais.

Essa abordagem traz à tona um importante problema enfrentado nos processos de intervenção pública, o choque entre os saberes locais e os peritos. Para entender essa multiplicidade, Long e Van Der Ploeg (1989) utilizam o conceito de "interface". Esta relação é onde as múltiplas realidades se confrontam; é a arena onde essa diversidade se mostra, pois, ao partilhar um mesmo "problema", os atores expõem suas diferentes expectativas, interesses e vivências. A análise das interfaces busca identificar essas múltiplas realidades para compreender de que maneira essas perspectivas, estratégias, culturas e categorias interagem entre si, as reproduzem e as transformam.

A diversidade de realidades se conecta a um ponto central em nossa pesquisa, o processo de aquisição do conhecimento, definido como "uma construção social e cognitiva, que resulta de e é constantemente desenhada pelas experiências, encontros e descontinuidades que emergem dos pontos de interação entre os diferentes mundos da vida dos atores". (LONG \& VEN DER PLOEG, 1989, p. 03, tradução nossa). Esse conhecimento tem o poder de influenciar as decisões nas 
práticas cotidianas. O poder, assim entendido, não é algo estanque, mas algo constantemente em definição, sendo a "capacidade de manipular, de negociar, de maneira a exercer alguma influência, controle, prerrogativa autoridade e capacidade de ação no processo" (Long \& Ploeg 1989, p. 03 - tradução nossa).

\section{OS PROGRAMAS DE ALIMENTAÇÃO ESCOLAR (PAEs)}

Os PAEs são políticas públicas direcionadas ao fornecimento de alimentação para os estudantes do ensino público. $O$ desenho desses programas recebe forte influência dos organismos internacionais, como a Organização das Nações Unidas (ONU) e a Organização Mundial da Saúde (OMS), que definem os marcos de atuação a serem seguidos, como o princípio do Direito Humano à Alimentação Adequada (DHAA). A implementação deste nos PAEs é realizada pelos países membros, que têm autonomia para organizá-los e desenvolvê-los. Inicialmente eram voltados ao combate à fome e à desnutrição, com o principal objetivo de reduzir a mortalidade infantil por desnutrição.

A partir de 1966, esses programas têm a influência também do Pacto Internacional sobre Direitos Econômicos, Sociais e Culturais (PIDESC), onde se redefinem e detalham os Direitos Humanos. $O$ direito à alimentação passa a ser caracterizado como um Direito à Alimentação Adequada (DAA), que é realizado quando "cada homem, mulher e criança, sozinhos ou em companhia de outros, têm acesso físico e econômico a todo tempo à alimentação adequada ou aos meios para sua aquisição". (UN, 1999, p. 3). Essa concepção abre a discussão sobre a qualidade do processo produtivo do alimento e sobre a importância da produção ambientalmente "sustentável".

O PNAE, no Brasil, é considerado o maior Programa de suplementação alimentar da América Latina, tendo em vista o tempo de atuação, desde 1954, a continuidade e o compromisso constitucional desde 1988 de universalidade e periodicidade (BELIK; CHAIM, 2009; TURPIN, 2015). O ano de 2009 se tornou um marco no PNAE, com o estabelecimento da Resolução FNDE/CD n ${ }^{\circ} 38$, que amplia a disponibilidade da AE também para o Ensino Médio e a Educação de Jovens e Adultos, bem como com a promulgação da Lei no 11.947, de 16 de junho de 2009, que estabelece a obrigatoriedade das Entidades Executoras de utilizarem pelo menos $30 \%$ dos recursos financeiros transferidos pelo FNDE na aquisição de 
gêneros alimentícios diretamente da Agricultura Familiar, isentando inclusive do processo licitatório.

Outra característica do PNAE é a obrigatoriedade do profissional nutricionista como responsável técnico para elaboração dos cardápios e o cuidado em respeitar os hábitos alimentares locais e culturais, atendendo às necessidades nutricionais específicas, conforme percentuais mínimos estabelecidos no artigo 14 da Resolução n 26/2013 (FNDE, 2013). Além da elaboração das refeições, o programa propõe a Educação Alimentar e Nutricional (EAN) com ações de conscientização sobre o que é alimentação adequada, envolvendo, sobretudo, alimentação, nutrição e sustentabilidade, temas transversais no currículo escolar (FNDE, 2006).

A bibliografia nacional sobre o PNAE é bastante voltada para a avaliação de sua implementação. Predominam os estudos na área da Nutrição e Saúde Pública cujos focos estão nos cardápios, dando destaque a como representar os conceitoschaves propostos pelo programa, como o da "alimentação adequada", no prato servido aos estudantes (POPITONE et. al. 2003; TEO; MONTEIRO, 2012; PEIXINHO, 2013).

A partir da área da gestão de recursos, em especial vindos da agronomia e desenvolvimento rural, os debates focam na implementação dos Programas de Aquisição de Alimentos (PAA) e sua integração ao PNAE (SZINWELSKI et al., 2015; MARQUES et al., 2014).

Ambas as abordagens se ocupam da temática da implementação dos novos conceitos trazidos pela $A E$. São perspectivas que buscam encontrar alternativas para que os leigos incorporem os conceitos trazidos pelos peritos do PNAE. Mas o confronto de saberes entre os leigos e os peritos não é tematizado. Nossa análise se diferencia ao mostrar que esse confronto é fundamental para a efetivação do programa e a formação de novos consumidores.

O FNDE, órgão financiador, normatizador, coordenador, monitor e fiscalizador do PNAE, repassa a verba para os estados e municípios, conforme a competência de cada instância ${ }^{3}$, que efetivam a compra dos alimentos solicitados, baseados nos cálculos das nutricionistas responsáveis. Em 2007, foram criados os Centros Colaboradores em Alimentação e Nutrição Escolar (CECANEs), para auxiliar no

\footnotetext{
${ }^{3}$ BRASIL. Sobre o Pacto Federativo na Gestão da Educação. Notícias. 02 de dez. 2014. Diponível em: http://www.portalfederativo.gov.br/noticias/destaques/pacto-federativo-saiba-o-papel-de-cadaente-da-federacao-na-gestao-da-educacao-publica. Acesso em 12 abr 2019.
} 
processo de educação e fiscalização dos repasses de recursos (BRASIL, 2009; FNDE, 2009). Em Santa Catarina, o CECANE localiza-se no Departamento de Nutrição da Universidade Federal de Santa Catarina (UFSC) desde 2007.

Outro ator responsável pela avaliação e monitoramento da implementação do Programa é o Conselho de Alimentação Escolar (CAE), formado por diversos atores (pais, alunos, representantes da secretaria de educação e de produtores rurais). $O$ CAE é um mecanismo de controle social, exercido pela comunidade escolar de forma voluntária. Foi instituído em 1994, quando iniciou-se o processo de descentralização de recursos ${ }^{4}$. Fazem parte ainda da estrutura de execução do PNAE, as secretarias de educação municipais e estaduais, responsáveis pela garantia das condições de infraestrutura e financeiras para a execução do PNAE como, por exemplo, o repasse dos recursos financeiros federais. Além destes, temse o coordenador da AE local, responsável técnico (nutricionista) e as merendeiras, responsáveis pela elaboração e distribuição da $A E$ na escola diretamente para os estudantes.

O Estado de Santa Catarina, por meio da Secretaria de Educação (SED), terceiriza a AE desde 2013 (nas escolas estaduais em Florianópolis, a empresa é a Risotolândia, desde 2014), sendo, então, a empresa terceirizada um ator importante nesse processo. $O$ contrato de serviço de alimentação escolar engloba a aquisição, preparo e serviços de distribuição da refeição, que é calculada por porção ${ }^{5}$ e deve ser controlada pela escola e pela empresa. As refeições devem seguir o cardápio elaborado pelas nutricionistas da SED. A empresa, assim, é responsável por todos os processos relacionados à alimentação, inclusive a compra da agricultura familiar (ponto 6.10 do contrato). Não conseguimos contato com nenhum responsável pela AE na empresa.

\section{OS ATORES E SUAS INTERFACES}

\subsection{ESCOLAS E A TERCEIRIZAÇÃO}

Entramos em contato com as escolas para a realização de visitas e entrevistas. Assim, percebemos que nem os diretores nem os professores

\footnotetext{
${ }^{4}$ FNDE. Sobre o CAE. Disponível em https://www.fnde.gov.br/index.php/programas/pnae/controlesocial-cae/sobre-cae Acesso em 06 jul. 2019.

${ }^{5}$ SED. Contratos de Alimentação Escolar. Disponível em: http://www.sed.sc.gov.br/documentos/alimentacao-escolar-2015-525/contratos-alimentacao-escolar Acesso em 09 nov. 2018
} 
conhecem o PNAE. Ao serem questionados sobre $A E$, imediatamente dizem que quem cuida é a empresa e que não podem ajudar muito. A SED apresenta a terceirização como algo que "alivia" a carga de atribuições da direção.

Os estudantes também mostram desconhecimento sobre o Programa e descrédito quanto aos aspectos saudáveis e sustentáveis da AE. Eles referem-se mais a "quem come e quem não come a merenda", ou "quais tipos de merenda preferem" (refeições ou lanches) em vez do alimento saudável ("merenda escolar" é o nome dado nas primeiras fases do Programa. A partir de 2000 a nomenclatura utilizada é "Alimentação Escolar", mas os estudantes ainda utilizam "merenda"). Sobre alimentação adequada, referem-se aos biomarcadores taxa de colesterol e diabetes, que aprenderam, na sua maioria, com as nutricionistas dos postos de saúde, em função de alguma disfunção nutricional. Quando perguntados sobre a EAN na escola, relataram apenas uma ocasião em que tinha um banner no refeitório.

As merendeiras essenciais no processo de transmissão de conhecimentos e percepções sobre alimentação, pois fazem os preparos e servem as refeições diretamente aos estudantes. Elas estão também em contato direto com as nutricionistas que acabam sendo as principais articuladoras do Programa, pois são elas que definem os cardápios, avaliam novas sugestões de preparo, novas receitas e fazem os cálculos das porções. Entre as merendeiras municipais (não terceirizadas), verifica-se uma autonomia para realização das receitas e interesse sobre o tema. Querem fazer parte do processo educativo, sem deixar de oferecer o sabor dos alimentos. Na formação do CECANE, as merendeiras pareciam muito engajadas. Já a merendeira com quem conversamos em Florianópolis, "terceirizada", não tinha quase nenhum conhecimento sobre o PNAE, mesmo estando há muitos anos trabalhando com isso. Os cursos de formação mediados pela empresa, segundo ela, são em geral ligados à seguridade alimentar e não ao PNAE.

A proximidade com os estudantes relevou também outro aspecto da percepção do saudável, e que também aparece nos discursos dos pais: a de que os estudantes são "apenas crianças" e que, então, não precisariam "passar por isso" (pela diminuição do sal, açúcar e gordura). 


\subsection{CONSELHO ESTADUAL DE ALIMENTAÇÃO ESCOLAR - CEAE}

Entramos em contato com o CEAE para participar de uma de suas reuniões. Nela, dois pontos foram centrais: 1) qualidade e quantidade das refeições; 2) resistência das empresas terceirizadas em efetuar compras da agricultura familiar.

É ponto pacífico entre os conselheiros que a terceirização precariza a alimentação, tanto em termos de qualidade quanto quantidade. Explicam que cada aluno tem direito a repetir uma vez a refeição, seguindo a recomendação nutricional. Há, portanto, uma quantidade de porções limitada. No entanto, o que alegam é que ao reduzir a quantidade das porções, a empresa continuaria ganhando o valor integral da porção, mas estaria servindo uma quantidade menor, procedendo então uma "economia" que visa, ao final do serviço, maior lucro. Conforme diagnóstico de uma das conselheiras, "empresa privada não faz filantropia", logo, o objetivo da empresa não é garantir a boa execução do PNAE. Há, então, uma contradição que leva ao segundo tema polêmico, a destinação do $30 \%$ dos recursos financeiros repassados pelo FNDE para a aquisição de gêneros alimentícios diretamente da agricultura familiar e do empreendedor familiar rural (BRASIL, 2009, ART. 14). De acordo com o que observaram em suas fiscalizações, a empresa não cumpre o estabelecido. É um entrave, pois embora o FNDE repasse o valor destinado a esses alimentos, as empresas privadas não realizam a compra do montante adequado.

\subsection{AGENTES DO CENTRO COLABORADORES EM ALIMENTAÇÃO E NUTRIÇÃO DO ESCOLAR - CECANE}

Após contato e entrevistas com as agentes do CECANE, 3 nutricionistas, pudemos acompanhar uma das formações integradas oferecidas pelo CECANE, que envolveu os 5 diferentes atores executores do PNAE: merendeiras, nutricionistas, gestores, CAEs e agricultores. A formação regional, de 2 dias, foi no município de Criciúma. Os principais temas trabalhados foram a) as atribuições de cada ator no programa; b) as diretrizes do programa; c) a definição de alimentação adequada; e, d) o significado da Educação Alimentar e Nutricional e o papel dos diversos atores em sua implementação.

Ao observar essa diversidade de atores e municípios com características também distintas (uns pequenos em que todos se conheciam, mas outros muito grandes impossibilitando o contato direto), identificamos diferentes demandas e problemas. Observamos na prática a importância da "vontade dos gestores" na 
implementação do programa. Esta opinião é partilhada pelas agentes do CECANE entrevistadas e pelas nutricionistas ouvidas no curso. Elas explicam que se os gestores não estiverem envolvidos com o Programa, eles não entenderão as escolhas alimentares sugeridas, que podem ser mais caras; além disso, não darão prioridade à contratação de profissionais da nutrição suficientes; muitas vezes, ainda, irão dificultar a compra da agricultura familiar, pois argumentam que os processos de compra são diferenciados, demandando mais trabalho para a gestão.

\subsection{AGRICULTORES FAMILIARES}

O contato com os agricultores foi também na formação do CECANE. Para eles, a valorização da produção local tem sido importante. O PNAE favorece a organização em sindicatos ou associações, meios de organização bastante fortes em Santa Catarina, pois beneficia a execução das exigências burocráticas do Programa. Os agricultores são otimistas com o PNAE, mas concordam que a maior dificuldade é, novamente, a vontade dos gestores, que acham o trâmite muito "burocrático". Por outro lado, vê-se que nos municípios menores, onde há maior produção familiar de alimentos, a oferta local é mais facilmente adquirida. Alguns municípios chegam a cerca de $80 \%$ dos recursos sendo destinados à aquisição da agricultura familiar. De acordo com os relatos do conselheiro do CEAE, representante dos agricultores, essa compra é realizada mais facilmente quando são as escolas que cuidam da AE. As empresas terceirizadas colocam ainda mais barreiras para essa aquisição.

\subsection{EMPRESA TERCEIRIZADA}

Não conseguimos contatar nenhum representante da empresa. Em todas as tentativas nos repassaram para vários setores e acabavam desligando.

\section{O DESCOMPASSO ENTRE TERCEIRIZAÇÃO E ALIMENTAÇÃO ESCOLAR}

A percepção sobre o que é considerado alimento adequado é central para a implementação do PNAE, pois dela depende o olhar integrador e educador. Há um descompasso entre a proposta de saudável do PNAE e a percepção dos atores entrevistados. Com esse descompasso, os gestores tendem a não se convencerem nem sobre os motivos da aquisição de alimentos "mais caros", nem da importância 
de se ter um profissional especializado que possa auxiliar na construção e difusão de EAN.

A escola é afetada negativamente pela terceirização de maneira direta, pois faz com que os atores ali presentes cotidianamente não se percebam como educadores de EAN. Ao estarem fora dessa atividade, afinal, quem faz o PNAE é a empresa, não se posicionam como parceiros no processo. Fica evidente a desconfiança com relação ao significado de "alimento saudável", sempre desqualificam a AE. Essa perspectiva associa-se a outra, muito forte, de que os estudantes são "apenas crianças" e que então não precisariam "passar por isso" (adequação alimentar). Ou seja, tem-se dois saberes locais que criam resistência, a desconfiança com o "nutricionalmente correto" e a emotividade para a qual o alimento não adequado (balas e doces) remete.

Colocando em interface as diferentes perspectivas, ou, as múltiplas realidades, identificamos diferentes saberes em disputa, deixando evidente 0 descompasso entre as definições propostas pelos PNAE e a sua prática cotidiana nas escolas. A multiplicidade de realidades se mostra inclusive nos cargos e funções na execução do PNAE, pois mesmo quando na mesma função, como entre as merendeiras e nutricionistas (que podem ser contratadas pela SED ou pela empresa terceirizada) suas instruções, vivências e visões de mundo podem ser muito distintas. Cada um desses atores traz uma experiência e traduz o alimento adequado a seu jeito. $\mathrm{Na}$ interface, essas diferenças podem surgir e com isso, claro, com muita negociação, novas noções, novos paradigmas podem ser criados.

Tal heterogeneidade não é um problema, necessariamente. Pelo contrário, entende-se que essa multiplicidade é rica na construção de novos conceitos e saberes; e que ao confrontarem-se, os atores co-constroem sua sociabilidade. No entanto, toda essa diversidade é neutralizada com a entrada da empresa terceirizada. Isso porque os atores não reconhecem e não se identificam com o objeto central, a AE. Os diferentes saberes continuam dispersos e não convergem.

O PNAE influencia positivamente as práticas alimentares. Não obstante, tratase de um processo de transição, em que esse nicho do alimento adequado está em busca da institucionalização no regime alimentar, mas como todo processo de transição depara-se com resistências. A terceirização é a resistência à mudança de um paradigma, que está saindo da visão da eficiência produtiva para uma visão de eficiência ecológica/ambiental. 
Fica claro, conforme Long e Van Der Ploeg (1989), que na realização prática das intervenções as coisas não funcionam exatamente como o planejado, devendo então ser constantemente avaliadas e repensadas para que objetivos e resultados convirjam. Pontuamos duas questões como fundamentais nesse processo: 1) a multiplicidade de conhecimentos que evidencia a aparente incompatibilidade entre 0 alimento adequado e o alimento gostoso; e, 2) como engajar os atores para uma implementação exitosa do Programa. Esses dois pontos são ainda agravados pela terceirização, que acaba sendo um mecanismo de dispersão, já que afasta os atores de sua funcionalidade no programa. O processo de terceirização ofusca a interação. A interface não se conclui, pois, a terceirização não deixa os atores se confrontarem.

Verifica-se, porém, que embora com desconfiança, receio e vergonha, ainda assim os atores locais mostram-se interessados no assunto. Ou seja, há um movimento em direção ao debate. É preciso que os pais, merendeiras e os demais atores cheguem num denominador comum entre o ideal do alimento adequado como delineado pela política pública e o realizável na prática cotidiana. Esse movimento deve ser de mão dupla, envolvendo tanto o saber local quando o perito (nutricionistas), permitindo a co-criação da transição para sustentabilidade.

\section{CONCLUSÃO}

Concluímos este artigo de forma otimista. Ainda que nossa pesquisa tenha um caráter exploratório, podemos observar que o PNAE é uma oportunidade de formação de novas práticas para transição. Trata-se de uma política pública de escopo nacional e de implementação local cuja principal proposição é educar para um consumo mais consciente, do ponto de vista da saúde pública e do meio ambiente. O desenho do PNAE e sua prática, até o momento, já conseguiram tirar da inércia a EAN; afinal os atores mostram saber que existe algum movimento, ainda desconhecido, mas que querem conhecer. Mostram-se constrangidos por não saber. Temos aí um ponto de partida importante. No entanto, vê-se que ainda há um longo caminho pela frente e embates importantes têm que serem enfrentados.

A inclusão da compra institucional da agricultura familiar possibilita a inclusão de uma nova forma de produção, distribuição e consumo, que pode incentivar (não há obrigatoriedade, mas abre precedentes para sua viabilidade) a produção de orgânicos e reduzir as distâncias entre produtor e consumidor. Isso permitiria uma 
possível transformação tecnocientífica, ainda que no nível do nicho. Do mesmo modo a perspectiva da alimentação adequada apresenta uma nova abordagem sociotécnica sobre o alimentar-se e sobre saúde, pontos fundamentais na transição para regimes sociotécnicos mais sustentáveis.

A dimensão da governança é ainda frágil. Embora o poder público tenha institucionalizado já as duas questões-chaves da alimentação adequada e da compra de produtos da agricultura familiar, ainda há um longo caminho para que os setores público e privado confluam para sua efetivação. Argumentamos que para que essas novas práticas extrapolem o nicho há a necessidade de uma maior aproximação com os atores locais, de modo a sensibilizá-los sobre o processo de fiscalização. Tal aproximação só pode ser realizada a partir de mecanismos "bottom up" que preconizam a horizontalidade dos processos, contando como fundamental para a efetividade dos projetos a participação dos atores, e não a mediação por empresas terceirizadas. 


\section{REFERÊNCIAS}

BELIK, Walter; CHAIM, Nuria Abrahão. O programa nacional de alimentação escolar e a gestão municipal: eficiência administrativa, controle social e desenvolvimento local. Revista de Nutrição, Campinas, v. 22, n. 5, p.595-607, out. 2009. FapUNIFESP (SciELO).DOI: http://dx.doi.org/10.1590/s1415$\underline{52732009000500001}$

BRASIL. Medida Provisória ${ }^{\circ}$ 2.178-34, de 28 de Junho de 2001. Dispõe sobre o repasse de recursos financeiros do Programa Nacional de Alimentação Escolar, institui o Programa Dinheiro Direto na Escola, altera a Lei $n^{\circ}$ 9.533, de 10 de dezembro de 1977, que dispõe sobre programa de garantia de renda mínima, institui programas de apoio da União às ações dos Estados e Municípios, voltadas para o atendimento educacional, e dá outras providências. Disponível em:

http://www.planalto.gov.br/ccivil 03/mpv/Antigas 2001/2178-34.htm Acesso 04 jul. 2019.

BRASIL. Constituição (2009). Lei $n^{\circ} 11947$, de 16 de junho de 2009. Dispõe sobre o atendimento da alimentação escolar e do Programa Dinheiro Direto na Escola aos alunos da educação básica; altera as Leis nos 10.880, de 9 de junho de 2004, 11.273, de 6 de fevereiro de 2006, 11.507, de 20 de julho de 2007; revoga dispositivos da Medida Provisória no 2.178-36, de 24 de agosto de 2001, e a Lei no 8.913, de 12 de julho de 1994; e dá outras providências.. Presidência da República Casa Civil: Subchefia para Assuntos Jurídicos. Brasília , Distrito Federal. Disponível em: http://www.planalto.gov.br/ccivil 03/ ato2007-2010/2009/lei//11947.htm Acesso em: 05 jul. 2019.

FUNDO NACIONAL DE DESENVOLVIMENTO DA EDUCAÇÃO (FNDE). Resolução $\mathbf{n}^{\circ} 33$ de 24 de agosto de 2006. Altera o disposto no art. $9^{\circ}$ da Resolução CD/FNDE $\mathrm{n}^{\circ}$ 032, de 10 de agosto de 2006. Disponível em:

https://www.fnde.gov.br/resolucoes/2006?start=10 Acesso em 04 jul. 2019.

FUNDO NACIONAL DE DESENVOLVIMENTO DA EDUCAÇÃO (FNDE). Resolução $\mathrm{n}^{\circ} \mathbf{3 8}$, de 16 de julho de 2009. Dispõe sobre o atendimento da alimentação escolar aos alunos da educação básica no Programa Nacional de Alimentação Escolar PNAE. Legislação. Brasília, DF, v. 280. Disponível em:

https://www.fnde.gov.br/acesso-a-informacao/institucional/legislacao/item/3341resolu\%C3\%A7\%C3\%A3o-cd-fnde-n\%C2\%BA-38-de-16-de-julho-de-2009. Acesso em: 01 jul. 2019.

FUNDO NACIONAL DE DESENVOLVIMENTO DA EDUCAÇÃO. Constituição (2013). Resolução $n^{\circ} \mathbf{2 6}$, de 17 de junho de 2013. Dispõe sobre o atendimento da alimentação escolar aos alunos da educação básica no âmbito do Programa Nacional de Alimentação Escolar - PNAE.. Legislação. Brasília, DF, v. 280. Disponivel em: https://www.fnde.gov.br/index.php/acesso-a- 
informacao/institucional/legislacao/item/4620-resolu\%C3\%A7\%C3\%A3o-cd-fnden\%C2\%BA-26,-de-17-de-junho-de-2013 Acesso em: 01 jul. 2019.

GUIVANT, Julia Silvia. Heterogeneidade de Conhecimentos no Desenvolvimento Rural Sustentável. Cadernos de Ciência e Tecnologia, Brasília, v. 3, n. 14, p.411446, dez. 1997.

HINRICHS, C Clare. Transitions to sustainability: a change in thinking about food systems change? Agriculture And Human Values, Si, v. 1, n. 31, p.143-155, mar. 2014.

HUI, Allison; SCHATZKI, Theodore; SHOVE, Elizabeth. Introduction. In: HUI, Allison; SCHATZKI, Theodore; SHOVE, Elizabeth. The Nexus of Practices: Connections, constellations, practitioners. Londres e Nova York: Routledge, 2017. p. 1-7.

LONG, Norman; PLOEG, Jan Douwe van Der. Demythologizing Planned Intervention: an Actor Perspective. Sociologia Ruralis, [s.l.], v. 29, n. 3-4, p.226249, dez. 1989. Wiley. DOI: http://dx.doi.org/10.1111/j.1467-9523.1989.tb00368.x

MARQUES, Amanda de Andrade et al. Reflexões de agricultores familiares sobre a dinâmica de fornecimento de seus produtos para a alimentação escolar: 0 caso de Araripe, Ceará. Saúde e Sociedade, [s.I.], v. 23, n. 4, p.1329-1341, dez. 2014. FapUNIFESP (SciELO). DOI: http://dx.doi.org/10.1590/s0104$\underline{12902014000400017}$

MINISTÉRIO DA SAÚDE \& MINISTÉRIO DA EDUCAÇÃO. Portaria Interministerial $\mathrm{n}^{\circ}$ 1010, de 8 de maio de 2006. Institui as diretrizes para a Promoção da

Alimentação Saudável nas Escolas de educação infantil, fundamental e nível médio das redes públicas e privadas, em âmbito nacional. Disponível em:

http://www.fnde.gov.br/acessibilidade/item/3535-portaria-interministerial-n\%C2\%BA1010-de-8-de-maio-de-2006 Acesso em 04 jul. 2019.

PEIXINHO, Albaneide Maria Lima. A trajetória do Programa Nacional de Alimentação Escolar no período de 2003-2010: relato do gestor nacional. Ciência \& Saúde Coletiva, [s.l.], v. 18, n. 4, p.909-916, abr. 2013. FapUNIFESP (SciELO). DOI: http://dx.doi.org/10.1590/s1413-81232013000400002

PIPITONE, Maria Angélica Penatti et al. Atuação dos conselhos municipais de alimentação escolar na gestão do programa nacional de alimentação escolar. Revista de Nutrição, [s.I.], v. 16, n. 2, p.143-154, jun. 2003. FapUNIFESP (SciELO). DOI: http://dx.doi.org/10.1590/s1415-52732003000200001 Disponível em: 
http://www.scielo.br/scielo.php?pid=S1415-

52732003000200001\&script=sci abstract\&tlng=pt Acesso em: 02 mai. 2019.

SCHATZKI, Theodore. The edge of change: on the emergence, persistence and dissolution of practices. In: SHOVE, Elizabeth; SPURLING, Nicola (Ed.). Sustainable practices: social theory and climate change. Londres e Nova York: Routledge, 2013. Cap. 3. p. 31-46.

SHOVE, Elizabeth; PANTZAR, Mika; WATSON. (Ed.) The dynamics of social practice: Every life and how it changes. Londres: Sage Publications Ltd, 2012. 191 p.

SPAARGAREN, Gert; OOSTERVEER, Peter; LOEBER, Anne. Sustainability Transitions in Food Consumption, Retail and Production. In: OOSTERVEER, Peter; LOEBER, Anne (Ed.). Food Practices in Transition: Changing Food Consumption, Retail and Production in the Age of Reflexive Modernity. Londres e Nova York: Routledge, 2012. Cap. 1. p. 1-34.

SZINWELSKI, Nádia Kunkel et al. Implicações Do Programa Nacional De Alimentação Escolar (Pnae) Na Renda E Organização De Agricultores Familiares. Revista Brasileira de Políticas Públicas, Brasília, v. 3, n. 5, p.221-240, jun./dez. 2015.

TEO, Carla Rosane Paz Arruda; MONTEIRO, Carlos Augusto. Marco legal do Programa Nacional de Alimentação Escolar: uma releitura para alinhar propósitos e prática na aquisição de alimentos. Revista de Nutrição, [s.l.], v. 25, n. 5, p.657-668, out. 2012. FapUNIFESP (SciELO). DOI: http://dx.doi.org/10.1590/s1415$\underline{52732012000500010}$

TURPIN, Maria Elena. A alimentação escolar como fator de desenvolvimento local por meio do apoio aos agricultores familiares. Segurança Alimentar e Nutricional, [s.l.], v. 16, n. 2, p.20-42, 10 fev. 2015. Universidade Estadual de Campinas. DOI: http://dx.doi.org/10.20396/san.v16i2.8634783

United Nations. Economic and social Council. Substantive Issues Arising In The Implementation Of The International Covenant On Economic, Social And Cultural Rights: General Comment 12. Geneva, 1999. Disponível em http://data.unaids.org/publications/external-documents/ecosoc cescr-gc14 en.pdf. Acesso em 27 nov. 2018. 